\title{
CAMINHOS PARA PROTEÇÃO DOS BABAÇUAIS E DOS SEUS DETENTORES CULTURAIS
}

MARIELLE RODRIGUES PEREIRA

Universidade Federal do Tocantins (UFT), Palmas, Tocantins, Brasil

DOI: http://dx.doi.org.br/10.11606/issn.1980-4466.v0i19p33-48

\section{RESUMO}

O artigo tem como objetivo refletir sobre a aplicação do Inventário Nacional de Referências Culturais (INRC) e o uso das indicações geográficas como instrumentos complementares às políticas de salvaguarda do patrimônio ambiental e cultural, no que tange à conservação da biodiversidade e à proteção da reprodução cultural, social, ancestral e econômica dos povos tradicionais da região norte do Tocantins que vivem em função do babaçu.

\section{PALAVRAS-CHAVE}

Populações tradicionais. Babaçu. INRC. Indicações geográficas. 


\section{WAYS TO PROTECT BABAÇUAIS AND ITS CULTURAL HOLDERS}

MARIELLE RODRIGUES PEREIRA

Universidade Federal do Tocantins (UFT), Palmas, Tocantins, Brasil

DOI: http://dx.doi.org.br/10.11606/issn.1980-4466.v0i19p33-48

\section{ABSTRACT}

The article aims to reflect on the implementation of INRC (National Inventory of Cultural References) and the use of geographical indications as instruments that complement the policies to safeguard environmental and cultural heritage. Especially, conserving biodiversity and protecting cultural, social, ancestral and economic production of traditional people from the northern region of Tocantins, whose lives revolve around the babaçu.

\section{KEYWORDS}

Traditional populations. Babaçu. INRC. Geographical indications. 
Ele também dá o óleo que tempera e faz sabão, lá no meio do sertão ele é apreciado.

Da casca faz o carvão, da palha o galpão, o caboclo do sertão dorme de pé espalhado'.

Quebradeiras de coco do babaçu do norte do Tocantins

Os babaçuais recobrem uma extensa faixa do território brasileiro na transição entre o cerrado e a floresta Amazônica. Trata-se de uma paisagem marcada por modos de vida típicos do Maranhão, Pará, Tocantins e Piauí, estados que contribuem para a rica biodiversidade do Brasil (CARRAZZA; FIGUEIREDO, 2010).

Sob as copas dos babaçuais (Orbignya phalerata) milhares de famílias extraem e quebram o coco babaçu, produzindo diversos produtos com o total aproveitamento da palmeira, como o óleo de amêndoa e o azeite; a massa gerada pela prensagem do óleo para alimentação dos animais, o mesocarpo, é nutritiva e medicinal; as cascas do coco se transformam em carvão; os troncos e palhas servem para a construção de moradias, vedação de paredes, cercas de lotes e a confecção de objetos artesanais.

1. Canto tradicional das quebradeiras de coco do babaçu no norte do estado do Tocantins. 
Da palha a gente faz o cesto, da casca a gente faz o carvão para nóis cozinhar, da amêndoa a vende para comprar os alimentos e para fazer o sabão para lavar roupa e tomar banho e para tirar o azeite para cozinhar. Também tira o leite para fazer no feijão, no peixe, numa fava para comer com farinha. Também a gente precisa da palha para envarar uma casa, fazer parede de uma casa, uma cerca. Nóis depende de tudo do babaçu. Da coqueira a gente não destrói nada. (SILVA, 2006)

Por tudo isso, as populações extrativistas nesses estados, em especial as quebradeiras de coco, lutam desde a década de 1980 para preservar essa palmeira, de valor socioambiental inestimável para a região, transformando seus usos e costumes tradicionais em produtos ofertados ao mercado.

No Tocantins, a extração do babaçu ocorre principalmente no extremo norte do estado, no Bico do Papagaio. Trata-se de um espaço onde existe uma estreita relação desses grupos extrativistas - reconhecidos como populações tradicionais ${ }^{2}$ - com esse elemento natural (o babaçu), que, apesar de existir uma política diferenciada em virtude da sua dimensão cultural, tem como marca um histórico de tensões, conflitos, mobilização de recursos e estratégias de enfrentamento ligado a questões territoriais, além de outros problemas cotidianos vinculados ao atendimento de suas necessidades.

A terra e o babaçu são os principais elementos para reprodução familiar desse grupo. Contudo, verifica-se que as condições acima descritas implicam "impedimento das atividades agroextrativistas e em significativas mudanças nas dinâmicas das relações sociedade-natureza. Implica, ainda, em embates entre os diversos atores relacionados à questão do babaçu" (ROCHA, 2011, p. 29), principalmente no que tange aos direitos territoriais de extração dos recursos naturais.

A Convenção 169 da Organização Internacional do Trabalho (OIT), incorporada ao ordenamento jurídico nacional por meio do Decreto $\mathrm{n}^{\circ}$

2. A expressão "populações tradicionais" é usada em uma acepção ampla, englobando os povos indígenas, os quilombolas, além das populações que estabelecem relações próprias e diferenciadas com a natureza, como os pescadores, os castanheiros, as quebradeiras de coco babaçu - grupos para os quais o território é um elemento essencial. 
5.051/2004, define territórios tradicionais como os espaços necessários à reprodução cultural, social e econômica dos povos e das comunidades tradicionais, determinando em seu artigo 14 que:

1. Dever-se-á reconhecer aos povos interessados os direitos de propriedade e de posse sobre as terras que tradicionalmente ocupam. Além disso, nos casos apropriados, deverão ser adotadas medidas para salvaguardar o direito dos povos interessados de utilizar terras que não estejam exclusivamente ocupadas por eles, mas às quais, tradicionalmente, tenham tido acesso para suas atividades tradicionais e de subsistência. Nesse particular, deverá ser dada especial atenção à situação dos povos nômades e dos agricultores itinerantes. 2. Os governos deverão adotar as medidas que sejam necessárias para determinar as terras que os povos interessados ocupam tradicionalmente e garantir a proteção efetiva dos seus direitos de propriedade e posse.

3. Deverão ser instituídos procedimentos adequados no âmbito do sistema jurídico nacional para solucionar as reivindicações de terras formuladas pelos povos interessados (BRASIL, 2004).

Contudo, pouco se avançou na garantia dos direitos territoriais de populações tradicionais que não se enquadram na definição de povos indígenas, comunidades quilombolas ou povos da floresta. No caso das quebradeiras de coco babaçu, mesmo após a criação da reserva extrativista do babaçu no Bico do Papagaio - Resex Extremo Norte do Tocantins - por meio do Decreto no 535/1992, a área passou mais de 10 anos ainda ocupada por fazendeiros e sem regularização fundiária.

O vídeo-documentário "Raimunda, a quebradeira", produzido por Marcelo Silva em 2006 no Bico do Papagaio, mostrou a relação das quebradeiras de coco com as florestas, denunciando a exploração da sua mão-de-obra, o corte e o envenenamento das palmeiras e a coleta indiscriminada do coco do babaçu inteiro pela indústria. O filme teve grande repercussão em âmbito nacional e internacional, trazendo vários benefícios para as famílias e motivando uma "série de iniciativas da sociedade e do poder público, 
fazendo-se ouvir o grito dos excluídos do babaçu e chamando a atenção para a devastação dos babaçuais" (Marcelo Silva, entrevista concedida em maio de 2013).

Como resposta à mobilização da comunidade que vive no Bico do Papagaio, principalmente das mulheres conhecidas como "quebradeiras de coco", e considerando os conflitos territoriais e os indícios de escassez da palmeira do babaçu - problemas que foram evidenciados no documentário em 2006 -, a Assembleia Legislativa de Tocantins aprovou, em 2008, a Lei no 1.959, com intuito de dar maior proteção para as famílias que sobrevivem da extração do babaçu.

Art. $1^{\circ}$. São proibidos a queima do coco babaçu, inteiro ou in natura, para qualquer finalidade, a derrubada e o uso predatório de suas palmeiras no Estado do Tocantins, vedadas ainda, as práticas que possam prejudicar a produtividade ou a vida do babaçu.

Art. $2^{\circ}$. As matas nativas constituídas por palmeiras de coco de babaçu, em terras públicas ou devolutas são de livre uso e acesso das populações agroextrativistas, desde que as explorem em regime de economia familiar e comunitário, conforme os costumes de cada região.

Parágrafo único. Em terras privadas, a exploração é condicionada à celebração de termo de acordo entre as associações regularmente constituídas de quebradeiras de coco de babaçu ou de comunidades tradicionais e os respectivos proprietários. (TOCANTINS, 2008)

Apesar de a chamada "lei do babaçu livre" ter sido aprovada no estado do Tocantins, as famílias que dependem desse recurso natural ainda se deparam com resistências por parte dos proprietários de terras em aceitá-las na mata, sobretudo devido ao arrendamento das terras para a empresa Tobasa Bioindustrial de Babaçu S.A. pelos fazendeiros da região, criando uma concorrência desleal para a obtenção do coco.

Nossa intenção não é questionar a inconstitucionalidade dessa lei e/ou a sua eficácia para proteger a comunidade da indisponibilidade do babaçu e da extração predatória por outros sujeitos sociais que não fazem 
parte do contexto cultural, social e econômico da população tradicional que vive na região norte do Tocantins. A questão fundamental é mostrar que essas famílias contribuem para a preservação da biodiversidade dessa região, representando formas próprias de organização social, utilizando-se do território e do babaçu para sua reprodução cultural, social, ancestral e econômica, sendo, portanto, reconhecidas oficialmente como população tradicional.

Essa relação dependente entre o ambiente natural e as comunidades tradicionais do babaçu, em especial as quebradeiras de coco, envolve uma dimensão de conhecimentos e práticas que são relevantes para a conservação da biodiversidade. Representa uma singularidade particular com a paisagem natural na qual elas estão inseridas, o que torna imprescindível conhecer as referências culturais que foram construídas ao longo do tempo no Bico do Papagaio.

Diante dessas preocupações que permeiam a viabilidade da proteção e para garantir a continuidade das práticas culturais dessa comunidade, a realização do Inventário Nacional de Referências Culturais (INRC) ${ }^{3}$ do Instituto de Patrimônio Histórico e Artístico Nacional (Iphan) se mostra como uma das alternativas de salvaguarda, com intuito de adquirir conhecimento sobre as referências culturais da região norte do estado em torno do elemento principal, o babaçu. Esse instrumento de identificação se torna importante para aferir as condições e práticas cotidianas realizadas tradicionalmente por essas populações, bem como identificar os detentores culturais dessas práticas com o objetivo de produzir conhecimento e provas sobre os bens culturais inseridos ao longo do tempo nessa região e que podem respaldar os direitos culturais coletivos desses sujeitos.

Outro caminho necessário, além do INRC e da garantia de extração do babaçu nas terras pela lei estadual, provavelmente será associar essas medidas a outros mecanismos de proteção para a valorização comercial da produção extrativista e artesanal a partir do babaçu.

No âmbito da propriedade intelectual, um instrumento que vem sendo muito discutido para agregar valor social, ambiental e cultural para

3. Instrumento de identificação e conhecimento de referências culturais realizado pelo Instituto do Patrimônio Histórico e Artístico Nacional (Iphan). 
determinados produtos e que poderia ser utilizado para os produtos originários da comunidade do babaçu corresponde às indicações geográficas (IGs).

Esse é um instrumento que pode proteger e agregar valor a um produto desenvolvido por povos indígenas, quilombolas e populações tradicionais, "considerando as suas identidades culturais e territoriais específicas, bem como os direitos territoriais e culturais conquistados principalmente a partir da Constituição Federal de 1988" (SANTILLI, 2005, p. 203).

As IGs foram direcionadas para criar mercados de produtos diferenciados, associados a determinados territórios, o que não impede que esses produtos também estejam associados a identidades culturais e regionais típicas e que se integram ao patrimônio cultural de origem, buscando o reconhecimento de sua forma própria em mercados dominados por mercadorias globalizadas, a partir da utilização dos instrumentos de propriedade intelectual.

Nesse sentido, essas indicações servem para destacar e valorizar produtos, bem como para proteger os seus produtores tradicionais, ao passo que a região, ao se tornar conhecida em razão da origem do produto principalmente se for um bem registrado como patrimônio cultural -, pode acabar atraindo uma concorrência desleal que prejudicaria as comunidades dos núcleos mais antigos de produção que sobrevivem dos recursos naturais pertencentes àquele território.

Ascensão (2008) relata que, em virtude desse processo de enfrentamento desleal no mercado, as IGs são restritas aos conjuntos de pessoas que são geograficamente delimitados e, quando registradas, constituem "propriedade comum dos residentes ou estabelecidos na localidade, região ou território, de modo efetivo e sério e podem ser usadas indistintamente por aqueles que, na respectiva área, exploram qualquer ramo de produção característica" (ASCENSÃO, 2008, p. 267).

Conforme Santilli (2009, p. 107), o "direito de uso das indicações geográficas é coletivo, e se estende a todos os produtores" reconhecidos tradicionalmente por desenvolver determinados produtos e que estão estabelecidos no território delimitado geograficamente.

A lei brasileira de propriedade industrial prevê o reconhecimento de indicações geográficas para produtos diferenciados vinculados a determinado espaço geográfico, reguladas na Lei nº 9.279/1996 (BRASIL, 1996), 
que estabelece os direitos e obrigações relativas à propriedade industrial, não restringindo o reconhecimento a produtos alimentícios e agrícolas.

Há duas espécies de indicação geográfica: a indicação de procedência (IP) e a denominação de origem (DO). Conforme a Lei ํํ 9.279/1996, a primeira corresponde ao nome geográfico de país, cidade, região ou localidade de seu território que se tenha tornado conhecido como centro de extração, produção ou fabricação de determinados produtos ou de prestação de serviços, independentemente de suas características ou qualidade intrínsecas. A segunda exige algo mais: além de tal vinculação, é necessário que o produto ou serviço guarde características e qualidades próprias que estão relacionadas ao território, incluídos os fatores naturais e fatores culturais diferenciados.

Contudo, se por um lado esse instrumento se mostra potencializador para agregação de valor de produtos elaborados por comunidades tradicionais, permite o acesso a mercados e impulsiona uma dinâmica de organização local dessas populações, garantindo maior confiança e proteção diante do mercado. Por outro, também exclui produtores que não se encontrem na área delimitada ou cuja produção não se conforme ao regulamento de uso. Ainda, em muitos casos, pode levar à padronização da produção e ao favorecimento de determinados grupos de produtores melhor articulados politicamente. Essas questões foram discutidas por Belas (2012) em sua tese de doutorado "Indicações Geográficas e Salvaguarda do Patrimônio Cultural: artesanato de capim dourado Jalapão-Brasil". A autora mostra que a insuficiente mobilização dos produtores, por parte das instituições locais responsáveis pela condução do processo de solicitação da IP da Região do Jalapão, resultou: 1) no aumento das desigualdades entre os artesãos que se encontram na área delimitada, favorecendo a comercialização dos núcleos mais recentes de produção em detrimento dos artesãos de núcleos mais antigos, que são justamente aqueles com menor infraestrutura e condições de acesso; 2) na exclusão de produtores tradicionais do território delimitado; 3) em imensas dificuldades de gestão, que até o presente têm inviabilizado o uso do selo por parte dos produtores; 4) na dependência técnica e financeira dos produtores de instituições locais responsáveis pela condução do processo; 5) na apropriação e uso político da IG por terceiros em detrimento dos próprios titulares.

Hoje, no Tocantins, o que está acontecendo com o babaçu e as famílias que dependem desse recurso natural para sobreviver é o mesmo 
que aconteceu no contexto inicial do capim dourado e a comunidade de Mumbuca, diante da política do poder público local, com apoio do Serviço Brasileiro de Apoio às Micro e Pequenas Empresas (Sebrae) e da iniciativa privada, que visa atingir novos mercados e contribuir para a geração de renda, sem refletir sobre os impactos que essas medidas poderiam causar aos recursos naturais, assim como aos detentores dos bens culturais inseridos na dinâmica da biodiversidade existente nesses territórios.

Várias são as indagações sobre a salvaguarda dos detentores dos bens culturais e o papel do poder público em relação às políticas públicas direcionadas ao mercado consumidor desses produtos, que possuem um valor simbólico e afetivo para as populações tradicionais, no caso as quebradeiras de coco e suas famílias, que possuem uma relação cultural estreita com o babaçu e o território.

A grande questão atualmente é a sustentabilidade ambiental, cultural e econômica do território das populações tradicionais. Isso "inclui a gestão sustentável de seus recursos naturais e a continuidade de suas práticas socioculturais coletivas, e de seus usos, costumes e tradições, consagradores da sua diversidade cultural" (SANTILLI, 2005, p. 197).

Para Raimunda Nonata Nunes Rodrigues, coordenadora da Associação de Mulheres do Bico do Papagaio (Asmubip), os grandes problemas enfrentados pelas quebradeiras de coco estão associados à concorrência desleal e à escassez do recurso natural devida à derrubada da palmeira, envenenamento das pidovas (espécie de brotos da palmeira do babaçu) e a coleta do coco inteiro pela indústria local.

E porque tem aí a Tobasa que ela faz a coleta do coco inteiro. Ela vai em cada comunidade e fala para o pessoal juntar o coco para elas. Eles pegam juntam aquele coco, não especialmente as mulheres, ali ele carrega o coco inteiro e vai se embora com o caminhão [...] e também se elas vendem o coco inteiro não têm lucro e ainda por cima sai da função de quebradeira, assim elas vão ser catadeira e a renda é menor. (Raimunda Nonata Rodrigues, entrevista publicada em 2006 no vídeo documentário de Marcelo Silva, Raimunda, a quebradeira) 
Existe uma rivalidade entre a associação das mulheres quebradeiras de coco e os catadores, pois estes interferem na renda das famílias das mulheres que exploram os subprodutos do coco, como o azeite, o óleo e o mesocarpo.

O coco tá difícil porque estão derrubando tudo de motosserra, aí tá difícil o coco porque eles pagam 10 peão para juntar o coco, e aí vem o caminhão de guincho e leva tudinho para a Tobasa. Aí nós não temos como quebrar o coco e fazer o azeite porque os fazendeiros estão vendendo o babaçu inteiro para eles com a casca mesmo. (Quebradeira não associada, entrevistada durante a produção do vídeo-documentário de Marcelo Silva em 2006)

Há uma tentativa da associação de eliminar a figura dos catadores, pois, apesar de eles justificarem a garantia da sobrevivência, essa situação gera a escassez do coco, constituindo-se como uma atividade predatória. A atuação desses sujeitos é incentivada pela obtenção de dinheiro rápido fornecido pela indústria local, que paga pelo coco inteiro e acaba influenciando as quebradeiras não associadas a se renderem ao sistema manipulado pela Tobasa. A empresa define o valor da amêndoa do coco a um preço muito baixo e cria condições de dependência das famílias aos atravessadores, ao passo que estes possuem postos de arrecadação da amêndoa e do coco inteiro que são mercearias onde as famílias vendem a amêndoa em troca de gêneros alimentícios de primeira necessidade.

O saco de arroz de cinco quilos é oito reais, aí o coco de sessenta centavos o quilo. A gente quebra de cinco a seis quilos por dia, ou seja, são dois dias quebrando coco para tirar um pacote de arroz. Isso quando o dia tá bom para quebrar o coco, pois quando a gente chega no babaçual e o proprietário está, ele chega e fala "Epa! Não quero ver ninguém quebrar coco aqui nas minhas terras, pode sair!”. (Quebradeira não associada, entrevistada durante a produção do vídeo-documentário de Marcelo Silva em 2006)

Existem locais no Bico do Papagaio, como no município de Pequizeiro, onde a associação das quebradeiras de coco não chegou. Neles, as mulheres 
não associadas se rendem ao sistema manipulado pela Tobasa, que define o valor do coco e da amêndoa para produzir o carvão vegetal, apesar de reconhecerem que a produção do azeite gera mais lucro para as famílias.

Por exemplo, se eu quebro dez quilos de coco e vendo a setenta centavos, ele vai dar sete reais por dia. E se eu quebrando esses cocos, deixando limpinho e fazendo o azeite eu tiro seis litros de azeite de dez quilos de coco. Tem vez que eu tiro até sete litros e aí eu vendo a três reais e cinquenta centavos o litro ou até quatro reais o litro. Eu acho que eu tiro mais lucro do que vender a amêndoa do coco. (Quebradeira não associada, entrevistada durante a produção do vídeo-documentário Marcelo Silva em 2006)

Mas as mulheres não associadas alegam que nem sempre podem fazer o azeite porque precisam de dinheiro rápido para sobreviver e comer no dia e encontram dificuldades para realizar a coleta do coco nas propriedades.

A existência de uma estrutura associativa ou de cooperativas fortes poderia ser uma garantia de sustentabilidade social (NASUTI; GREISSING; MARCHAND, 2010), visto que o benefício obtido com esses mecanismos de valorização pode ser distribuído de maneira equitativa. Entretanto, as associações existentes na região do Bico do Papagaio não chegam a todos os locais da área de abrangência dos babaçuais onde há famílias que sobrevivem desse recurso natural.

A inserção da IG Bico do Papagaio poderia incentivar a adesão de um número maior de quebradeiras às associações e viabilizar a eliminação da figura dos "atravessadores" do processo de comercialização dos produtos desenvolvidos pelas famílias que dependem e sobrevivem do babaçu, principalmente nas áreas onde as mulheres ainda não participam de uma associação. Mas é preciso alertar que esse instrumento deve estar associado à efetividade do cumprimento de uma legislação que impede a cata predatória do coco para o fornecimento da indústria, pois o Acordo sobre Aspectos dos Direitos de Propriedade Intelectual Relacionados ao Comércio (ADPIC) "negligencia as relações específicas que podem existir entre homens e natureza, focando apenas sobre os 'saber fazer' dos IG's" (NASUTI; GREISSING; MARCHAND, 2010), o que pode não garantir a preservação da biodiversidade. Por isso a necessidade de acompanhamento 
e de uma legislação ambiental para o uso e manejo do recurso natural que seja eficaz e eficiente.

Outro ponto que merece ser ressaltado é que as IGs poderiam incentivar o aumento do valor de mercado dos produtos desenvolvidos pelas comunidades que vivem em torno do babaçu, desde a quebra do coco até a produção do azeite, com fiscalização do processo, visto que é um item reconhecido por ser produzido na região dos babaçuais, chamada Bico do Papagaio.

Além do risco de as quebradeiras se tornarem catadeiras, há ainda um preconceito em relação à técnica de quebrar coco manualmente, que é vista como arcaica e rudimentar por aqueles que defendem a inserção de tecnologias modernas e que tentam incentivar as quebradeiras a mecanizar a produção extrativista do babaçu, principalmente a indústria local, a Tobasa, que patenteou a máquina de quebrar coco para extrair a amêndoa.

De tal situação surgem as controvérsias, em que cada ator tem suas motivações e justificativas para as suas ações. De um lado, as quebradeiras de coco babaçu que praticam o extrativismo sem prescindir das formas tradicionais de coleta e quebra do coco, do outro lado, empresários e indústria que justificam suas demandas por uma inovação tecnológica para a quebra do coco babaçu a partir da lógica da acumulação e do utilitarismo da extração da amêndoa do babaçu.

As quebradeiras de coco babaçu fundamentam suas ações presentes na tradição do passado repassada de geração a geração. Frases como: "minha mãe me ensinou", "eu aprendi assim", "desde pequena eu quebro coco do mesmo jeito", "eu fui criada com o babaçu" apontam para a tradição no sentido dado por Hobsbawm (1998), que entende a tradição na medida em que há referência a um passado histórico. Para o autor, o tradicional é um conceito que tenta captar algumas permanências históricas específicas que remetem a práticas rituais e simbólicas reguladas por regras que orientam formas de comportamentos centrados na repetição (ROCHA, 2011, p. 158).

Diante desse impasse, é visível a necessidade de documentar essas 
práticas que foram passadas por várias gerações em função do babaçu a partir da utilização do INRC, antes que esses processos sejam mutilados, principalmente pela indústria local, que impõe o valor do coco ao mesmo tempo que incentiva a perda dessas práticas por meio da cata predatória do coco e da inserção de tecnologia patenteada para a quebra do fruto em benefício próprio.

Assim, o INRC documenta e pode viabilizar a proteção dessas práticas que estão fadadas à extinção. Mas também é preciso oferecer meios para que essa comunidade tradicional que vive no Bico do Papagaio e que depende do babaçu consiga competir equitativamente no mercado manipulado pela indústria local, com intuito de melhorar a qualidade de vida de suas famílias e garantir a manutenção de suas práticas tradicionais que são fundamentadas nesse importante recurso natural.

Nesse sentido, talvez possamos pensar na adoção dos mecanismos da propriedade intelectual, no que tange à IG, associada aos instrumentos do Iphan para proteger as práticas culturais dessas famílias, bem como defendê-las do mercado competitivo e desleal que ocorre nessas regiões.

As indicações geográficas se mostram como sinais distintivos que agregam valor ao produto ou serviço e geram riqueza, além de atestar a origem geográfica, o que para o consumidor é uma garantia de identidade própria e inconfundível e uma motivação para pagar um preço maior.

É importante salientar que, além da participação da comunidade para a realização do INRC, deve haver uma forte articulação das quebradeiras de coco e suas famílias em todo o processo de obtenção do selo da IG para definição das normas de proteção e regulamento de qualidade para inserção dos subprodutos do babaçu no mercado a partir da demanda dos seus detentores culturais que dependem da palmeira para sua sobrevivência.

Surge, porém, um obstáculo de natureza cultural no Tocantins, onde não ocorre a valorização de produtos diferenciados. Portanto, algum esforço deve ser feito no sentido de esclarecer os consumidores a respeito dos sinais distintivos, apesar de as políticas de estímulo ao consumo dos produtos tradicionais visarem aos mercados externos.

Aspecto importante a ser destacado é o efeito contrário que a política das IGs pode causar ao se estabelecerem excessivas normas de produção, principalmente quando há intervenção de outros profissionais, como dos 
designers, que definem uma padronização rigorosa do produto, como aconteceu com o capim dourado. Essa interferência exagerada pode resultar na homogeneização desses produtos, reduzindo a sua diversidade e retirando a sua identidade - elemento motivador da obtenção de IG em razão das particularidades desses produtos que os diferenciam no mercado globalizado. Por isso, reafirmamos a importância e a necessidade da participação, articulação e autonomia dos detentores dos bens no processo de aquisição da IG.

\section{REFERÊNCIAS}

ASCENSÃO, José de Oliveira. Questões problemáticas em sede de indicações geográficas e denominações de origem. In: ASSOCIAÇÃO PORTUGUESA DE DIREITO INTELECTUAL. Direito industrial. Coimbra: Almedina, 2008. p. 253-269.

BELAS, Carla A. O consumo de bens culturais e a salvaguarda do patrimônio imaterial: o caso do capim dourado do Jalapão. 2011. Disponível em: <http://www.acasa.org.br/biblioteca_texto. php?id=369>. Acesso em: 28 maio 2015 .

Indicações geográficas e a salvaguarda do patrimônio cultural: artesanato de capim dourado Jalapão-Brasil. 2012. 266 f. Tese (Doutorado em Desenvolvimento, Agricultura e Sociedade) - Universidade Federal Rural do Rio de Janeiro, Rio de Janeiro, 2012.

BRASIL. Lei no 9.279, de 14 de maio de 1996. Regula direitos e obrigações relativos à propriedade industrial. Diário Oficial da União, Brasília, DF, 15 maio 1996.

Decreto nº 5.051, de 19 de abril de 2004. Promulga a Convenção no 169 da Organização Internacional do Trabalho - OIT sobre povos indígenas e tribais. Diário Oficial da União, Brasília, DF, 20 abr. 2004. p. 1.

CARRAZZA, Luis; FIGUEIREDO, Isabel (Orgs.). Cerrado que te quero vivo! Produtos e meios de vida sustentáveis apoiados pelo Programa de Pequenos Projetos Ecossociais (PPP-ECOS). Brasília: Instituto Sociedade, População e Natureza, 2010.

NASUTI, Stéphanie; GREISSING, Anna; MARCHAND, Guillaume. Criação de áreas protegidas, uso sustentável de recursos naturais emblemáticos e valorização do patrimônio cultural: uma síntese bem-sucedida na Amazônia brasileira?. ALASRU - VIII Congreso Latinoamericano de Sociología Rural. Porto de Galinhas, PE, 2010.

ROCHA, Maria Regina Teixeira da. A rede sociotécnica do babaçu no Bico do Papagaio - TO: Dinâmicas da relação sociedade-natureza e estratégias de reprodução social agroextrativista. 2011. 252 f. Tese (Doutorado em Desenvolvimento Rural) - Universidade Federal do Rio Grande do Sul, Porto Alegre, 2011.

SANTILLI, Juliana. As indicações geográficas e as territorialidades específicas das populações tradicionais, povos indígenas e quilombolas. In: LAGES, Vinicius (Org.). Valorização de produtos com diferencial de qualidade e identidade: indicações geográficas e certificações para a competitividade nos negócios. Brasília: Sebrae, 2005. p.189-203. 
. As indicações geográficas e as territorialidades específicas das populações tradicionais, povos indígenas e quilombolas. Instituto do Patrimônio Histórico e Artístico Nacional (Org.). Contribuição dos palestrantes da $8^{\mathrm{a}}$ oficina PEP (Petrópolis 2008). Coleção Cadernos de estudos do PEP, v. 9, Rio de Janeiro: Iphan, 2009. p. 105 -114.

SILVA, Marcelo (Dir.). Raimunda, a quebradeira. Coprodução: Marcelo Silva; Public Produções; TV Palmas; Fundação Padre Anchieta. 2006. 1 DVD (52 min.), NTSC, son., color.

TOCANTINS. Lei no 1.959 , de 14 de agosto de 2008. Dispõe sobre a proibição da queima, derrubada e do uso predatório das palmeiras do coco de babaçu e adota outras providências. Diário Oficial do Estado do Tocantins, Palmas, TO, 15 ago. 2008. p. 1-2.

RECEBIDO EM: 04/03/2015

APROVADO EM: 06/05/2015

\section{MARIELLE RODRIGUES PEREIRA}

Mestre em Preservação do Patrimônio Cultural pelo Instituto do Patrimônio Histórico e Artístico Nacional (IPHAN), graduada em Arquitetura e Urbanismo pela Universidade Federal do Tocantins e professora dos cursos de Engenharia Civil da Universidade Federal do Tocantins e de Arquitetura e Urbanismo do Centro Universitário Luterano de Palmas. E-mail: mariellerodriguez@yahoo.com.br. 